\title{
El aprendizaje del español como lengua extranjera: la importancia de utilizar el diccionario adecuado
}

\author{
RAFAEL ONIEVA PALOMAR \\ Universidad de Granada \\ rafa13@correo.ugr.es
}

Resumen: La lengua española es estudiada por millones de personas en todo el mundo, dada su gran importancia en la sociedad actual. Sin embargo, los diccionarios no son aprovechados al máximo por los estudiantes, ya que, generalmente, estos usan el diccionario bilingüe durante toda su trayectoria de aprendizaje. Además, estos cuentan con el beneplácito de los docentes, a pesar de la existencia de otras obras lexicográficas que se adaptan mejor a las diferentes etapas que existen en el aprendizaje de un idioma extranjero.

Palabras clave: español como lengua extranjera, lexicografía, diccionario bilingüe, diccionario de aprendizaje.

\section{Learning Spanish as a foreign language: the importance of using the right dictionary}

Abstract: The Spanish language is learnt by millions of people all around the world, due to its great importance in the current society. However, students do not take full advantage of dictionaries, since, generally, they only use bilingual dictionaries throughout their whole learning process. Besides, teachers green-light their usage, even though there are other dictionaries that may adapt in a better way to the different stages that exist when learning a foreign language.

Keywords: Spanish as a foreign language, lexicography, bilingual dictionary, monolingual learner's dictionary.

\section{Introducción}

No cabe duda de que el español es una lengua de gran importancia a nivel mundial en la actualidad, ya que es la segunda lengua con más hablantes nativos en la actualidad (más de 480 millones de personas), tan solo superada por el chino mandarín. Esto provoca que se le dé una gran importancia al español en la educación de los países no hispanohablantes y que se enseñe en un total de 107 países en la actualidad. El papel del español es especialmente relevante en los países anglófonos, hasta tal punto que es el idioma extranjero más estudiado en Estados Unidos y en Reino Unido es percibido como la lengua extranjera más importante para el futuro (IC, 2018: 5-11). 
Así pues, dada la innegable importancia del español como lengua extranjera, en este artículo se pretende dar cuenta de cómo son algunas obras lexicográficas destinadas a este fin. Para ello, se ha elegido el primer diccionario monolingüe en lengua española dirigido a estudiantes de E/LE y, por ende, fundador de los denominados diccionarios de aprendizaje: el Diccionario para la enseñanza de la lengua española (DiPELE) (1995), publicado por la editorial VOX-Biblograf en España, impulsado por la Universidad de Alcalá de Henares y dirigido por Manuel Alvar Ezquerra. Para el análisis de un diccionario biligüe, se ha tomado como referencia el Vox English and Spanish Learner's Dictionary (VOX-NTC), publicado también por la editorial VOX, esta vez en Estados Unidos, con la colaboración de NTC/Publishing en el año 1998.

En consecuencia, el objetivo de este artículo es discernir si estos diccionarios se adecúan a las características que deben tener las obras lexicográficas pertenecientes a las categorías en las que estos se encasillan según parámetros propuestos por reputados lexicógrafos. De esta manera, se quiere comprobar si estos diccionarios son recomendables para los estudiantes a los que, teóricamente, van dirigidos o no. A partir de este análisis, se realizará un estudio contrastivo entre ambas obras para comprobar qué hay en común y qué no en la estructura de estos diccionarios. Se parte de la hipótesis de que, al ser dos diccionarios cercanos en el tiempo y editados por las mismas editoriales, estos contarán con una macroestructura y microestructura similares.

\section{Estado de la cuestión}

\subsection{EI diccionario visto desde una perspectiva de mercado}

El aprendizaje de una lengua, bien sea la materna o una extranjera, tiene como una de sus principales características el uso de diccionarios. Aunque pueda parecer una perogrullada, no todos los diccionarios pueden ser utilizados por los mismos usuarios ni en los mismos niveles del aprendizaje de la lengua, puesto que cada obra lexicográfica está adaptada a un público diferente. Sin embargo, hay que tener muy presente que los diccionarios son un producto comercial y que su edición está sujeta a la ley de la oferta y la demanda. Por lo tanto, las editoriales publicarán exclusivamente aquellos diccionarios que consideren que les reportarán un mayor beneficio económico y crean que pueden ser adquiridos por un mayor número de compradores (Rodríguez Barcia, 2016: 96). No hay que olvidar que, tal y como señalaron autores reconocidos en el mundo de la lexicografía, como Dubois (1971): «el diccionario es en primer lugar un objeto manufacturado y por tanto de carácter comercial».

\subsection{Lexicografía bilingüe y lexicografía didáctica: diferencias}

El diccionario bilingüe es una herramienta en la cual aparecen las equivalencias léxicas entre la L1 y la L2 que se estén tratando. Normalmente, es bidireccional, es decir, ambas lenguas están presentes en un mismo tomo. La inclusión de ambos idiomas provoca que el número de entradas suela ser bastante inferior con respecto a los diccionarios monolingües, lo que puede entenderse como un hándicap a la hora de ser usados por los estudiantes. Además, suelen limitarse a dar el equivalente léxico más aproximado en la lengua meta y, en consecuencia, no se define el término (Alvar Ezquerra, 1993: 147). Este tipo diccionario, por lo tanto, es útil para una primera toma de contacto con un idioma extranjero y su uso debe restringirse a las fases iniciales del aprendizaje, puesto que limita en demasía la capacidad de producción del alumno (Contreras Izquierdo, 2000: 658). 
Por otra parte, en los diccionarios de aprendizaje se engloban todos aquellos diccionarios monolingües que están dirigidos a usuarios extranjeros. Se recomienda su uso a aquellos estudiantes extranjeros que tienen un nivel medio-avanzado en lengua española, puesto que los diccionarios bilingües no satisfacen todas sus necesidades por las carencias nombradas anteriormente y estos alumnos no están aún capacitados para usar un diccionario monolingüe general. Por lo tanto, estos diccionarios pueden ser considerados como el paso intermedio en el aprendizaje de español como lengua española, dado su marcado carácter didáctico y la adaptación de su macroestructura y microestructura a personas extranjeras (Prado Aragonés, 2005: 22-23).

Es destacable que el español, en comparación con el inglés, lleva varias décadas de retraso en lo que se refiere a diccionarios de aprendizaje. Esta categoría, conocida como learner's dictionaries, tuvo sus comienzos en la lexicografía anglosajona en la década de los 40, con el Idiomatic and Syntactic English Dictionary (1942) y el Oxford Advanced Learner's Dictionary of Current English (1948) (Pablo Núñez, 2017: 208). Hernández Hernández denuncia en el primer congreso de ASELE (1990) la falta de apoyos de las instituciones responsables en promover la lengua española y la inexistencia de diccionarios de este corte en la lexicografía española. Esto acarreaba que una gran parte del público extranjero no tuviera un diccionario específico para su nivel, con las repercusiones negativas que esto acarreaba tanto en el aprendizaje del español como en el mercado lexicográfico (Hernández Hernández, 1990: 159-161).

\section{3. Éxito comercial de los diccionarios bilingües frente a los monolingües en E/LE}

A pesar de las limitaciones ya descritas de los diccionarios bilingües, estos son altamente demandados por los usuarios. Esto se debe a la facilidad con la que se puede obtener un equivalente del término que se está buscando en el idioma deseado sin necesidad de tener que indagar en obras más densas. Además, en muchas ocasiones el docente, por desconocimiento del abanico de obras lexicográficas existentes, se limita a recomendar a sus estudiantes un diccionario bilingüe en las clases de lenguas extranjeras, indiferentemente del nivel de competencia de sus alumnos (Prado Aragonés, 2005: 19).

El éxito de los diccionarios bilingües frente al resto en el aprendizaje de lenguas extranjeras se puede refrendar con numerosos estudios que se han realizado. Contreras Izquierdo hizo una investigación tomando como referencia a alumnos de $\mathrm{E} / \mathrm{LE}$ de nivel medio-avanzado en el que se concluía que estos utilizaban diccionarios bilingües principalmente para ahorrar tiempo, encontrar rápidamente un equivalente en la lengua meta y a su precio, mucho más reducido que el de los diccionarios monolingües (Contreras Izquierdo, 2000: 661-662).

Azorín Fernández y Climent de Benito encuestaron en el año 2005 a 183 estudiantes extranjeros de español de la Universidad de Alicante sobre el uso del diccionario en sus clases. Obtuvieron como resultado que un 94,5\% de ellos utilizaba un diccionario bilingüe, frente al paupérrimo $30 \%$ que tenían un diccionario de aprendizaje. Los autores destacan que un $47 \%$ había adquirido ese diccionario por criterio propio y no por recomendación del docente lo que provoca, mayoritariamente, una mala elección por parte del comprador. Esto es debido a que el conocimiento de los estudiantes sobre los diccionarios es, mayoritariamente, escaso y el juicio que pueden emitir acerca del diccionario se apoya tan solo en cuestiones extralingüísticas tales como el precio, el tamaño o la publicidad que las editoriales hagan del diccionario en cuestión. Esto ocasiona, según estos expertos, que las editoriales se dediquen a hacer un gran esfuerzo 
en la parte extralingüística del diccionario y tengan más en cuenta estos aspectos que los propios aspectos lingüísticos a la hora de lanzar un diccionario al mercado (Azorín Fernández y Climent de Benito apud Azorín Fernández y Martínez Egido, 2010: 95-96).

\subsection{La lexicografía electrónica en el plano de $\mathrm{E} / \mathrm{LE}$}

El uso de diccionarios electrónicos es un concepto claramente en auge dentro del mundo de la lexicografía. En los países asiáticos, principalmente, se usan los denominados Diccionarios Electrónicos Portátiles (DEP), que son pequeños dispositivos que cuentan con un teclado y una pantalla donde aparecen los resultados. Estos dispositivos tienen un alto grado de aceptación entre los estudiantes, aunque los docentes no siempre apoyan su uso. Estos creen que los alumnos hacen búsquedas innecesarias, son ruidosos y frenan el salto de los estudiantes al diccionario monolingüe. Los alumnos, por su parte, señalan que pueden hacer búsquedas de una manera más rápida que con un diccionario en papel y son más cómodos en su utilización. Cabe destacar que el $96 \%$ de los estudiantes de español (de un total de 211) de la Universidad de Aichi (Japón) poseen un DEP y el grado de satisfacción de los estudiantes es de un $73 \%$. Además, un $62 \%$ de los estudiantes aseguraba haber utilizado un diccionario electrónico antes de comenzar su etapa universitaria. Los estudiantes también señalan que, mayoritariamente, el aprendizaje del uso del diccionario se ha llevado de manera autodidacta, puesto que las instrucciones que recibían por parte de los docentes eran similares a las que estos otorgaban con los diccionarios en papel. Este desconocimiento por parte de los docentes acarrea, entre otras cosas, en unas pobres habilidades lexicográficas de los estudiantes que, por ende, no pueden sacar el máximo partido de estos diccionarios (Sala Caja, 2015: 855-859).

\section{Metodología}

El corpus de esta investigación está compuesto por las obras lexicográficas DiPELE y VOX//NTC. Como uno de los objetivos que se plantean en esta investigación es comprobar si estos diccionarios son apropiados para los usuarios a los que, teóricamente, van dirigidos, se van a analizar estos diccionarios a partir de una serie de criterios ideados por expertos en lexicografía. Para analizar el DiPELE, se van a tomar como referencia los criterios de evaluación propuestos por Azorín Fernández y Martínez Egido (Azorín Fernández y Martínez Egido, 2010: 109-110). Aunque el objetivo que los autores persiguen con esta plantilla de evaluación sea evaluar los diccionarios en una escala de 0 a 150 puntos, en esta investigación me ceñiré a comprobar exclusivamente si el DiPELE cuenta o no con los apartados que se exponen sin entrar a valorar numéricamente el grado de satisfacción con el que lo cumplen. La plantilla de evaluación que estos estudiosos proponen se desglosa en cuatro grandes apartados, que corresponden con las partes que componen un diccionario, es decir, la hiperestructura, macroestructura, microestructura e iconoestructura. Dentro de cada apartado, se enumeran los diferentes subapartados (cada uno de ellos se evalúa del 0 al 5):

1) Microestructura: guía de uso, explicación del metalenguaje, apéndices y guía conversacional.

2) Macroestructura: léxico de civilización actual, léxico coloquial/tabuizado, léxico inventarios Instituto Cervantes, americanismos, abreviaturas/siglas, léxico específico y léxico literario/formal.

3) Microestructura: información sobre la ortografía, la pronunciación, la silabación, la homonimia/paronimia, la flexión nominal, la flexión verbal, la 
combinación sintática, la combinación semántica, el orden de las palabras, las relaciones paradigmáticas, información cultural, presencia de definiciones adaptadas, ejemplificaciones, explicación de las Unidades Fraseológicas (Ufs) y marcas de uso.

4) Iconoestructura: variedad de los tipos de letra, valor de las ilustraciones, distribución del artículo y símbolos/abreviaturas.

Por otra parte, para discernir si un diccionario bilingüe es apropiado o no, Haensch propone una serie de 14 parámetros para valorar positiva o negativamente un diccionario bilingüe (Haensch, 2003-2004: 133-138). De la misma manera, me ceñiré a comprobar qué parámetros existen en el VOX/NTC y cuáles no para decidir si el diccionario que se analiza es apropiado o no. Esta vez, los parámetros no están organizados como en la clasificación anterior, sino que el autor plantea una serie de cuestiones para delimitar la calidad del diccionario bilingüe. A continuación, se procederán a enumerar los parámetros propuestos por Haensch:

1) Grupo de destino. ¿Se especifica en el título o la introducción a qué usuarios va dirigido el diccionario?

2) Introducción gramatical. ¿Se hace en ambas lenguas? ¿Se conjugan elementos que pueden acarrear dificultades a los extranjeros?

3) Pronunciación. ¿Está presente en ambas lenguas con su transcripción fonética?

4) Instrucciones para el usuario. ¿Son claras y suficientes para el usuario?

5) Gramática. ¿Se usan marcas gramaticales? ¿Se indica la categoría a la que pertenecen las palabras? ¿Se indica el género? ¿Se indica el régimen preposicional de verbos, adjetivos y sustantivos?

6) Fraseología. ¿Está presente en el diccionario?

7) Ejemplos. ¿Se ofrecen ejemplos en forma de frase-ejemplo? ¿Proceden de un corpus o son inventadas por los lexicógrafos?

8) Selección del léxico. ¿Es acertada la selección del léxico? Es decir, ¿hay léxico de nuestra civilización actual? ¿Están presentes el lenguaje coloquial y vulgar? ¿Hay presencia de americanismos usuales?

9) Fiabilidad de equivalentes. ¿Son los equivalentes más precisos y adecuados en la lengua de destino?

10) Abreviaturas y siglas. ¿Se registran las abreviaturas más habituales?

11) Acotación exacta de las distintas acepciones de una palabra. ¿Hay uso de marcas lexicográficas y glosas?

12) Orden alfabético. ¿Aparecen la $\mathrm{CH}$ y la LL como letras independientes?

13) Innovaciones. ¿Están las letras impresas en otro color? ¿Hay culture specific words, es decir, palabras prácticamente intraducibles a otro idioma como flamenco? ¿Se hace referencia a los falsos amigos?

14) Otros extras. ¿Hay una introducción a la civilización de los países donde la lengua que se estudia es la materna? ¿Se presenta una guía de conversación en situaciones cotidianas? 


\section{Análisis}

\subsection{Análisis de los diccionarios}

\subsubsection{Análisis del DiPELE}

En relación con su hiperestructura, este supera con éxito todos los puntos excepto el último (guía conversacional), puesto que carece de ella. Con respecto a los otros tres puntos (guía de uso, explicación del metalenguaje y apéndices), el DiPELE los supera al aportar una guía para consultar el diccionario que tiene un claro carácter descriptivo y que ayuda al usuario a conocer la microestructura de una manera sencilla. Se explica el metalenguaje al haber un extenso apartado dedicado explícitamente a la fonología y otro a las abreviaturas del diccionario. Finalmente, se incluye un amplio apéndice gramatical de 45 páginas, donde se explican minuciosamente todas las clases de palabras y se ofrece una lista con 92 verbos irregulares.

La macroestructura de este diccionario está compuesta por «22000 voces seleccionadas a partir de criterios científicos» (Alvar Ezquerra, 1995). Estos criterios corresponden a estudios de frecuencias, léxicos básicos del español, manuales de español para extranjeros, el Corpus Vox-Biblograf y palabras comunes en prensa y literatura española contemporánea (Moreno Fernández, 1995: XI). En referencia al subgrupo 'léxico de civilización actual', cabe destacar que este es un concepto extremadamente amplio y en el que se pueden abarcar varios tipos de voces, por ejemplo de carácter tecnológico. Si nos atenemos a lo expuesto en el proceso de selección de los términos, deben aparecer voces que se inscriban dentro de este grupo al tomar como referencia, entre otros, manuales de ELE actuales o palabras comunes en prensa. El léxico coloquial/tabuizado estaría representado por las marcas fam., infor. y vulg, el específico por toda las marcas relacionadas con la terminología, como pueden ser ZOOL., QUÍM., LING o ECON. Finalmente, el léxico literario está representado por LIT. y, si se incluyen en esta categoría voces de un registro elevado, form. Dada la no inclusión de marcas relacionadas con americanismos y siglas/abreviaturas, se descarta la existencia de voces pertenecientes a estos grupos.

Como se explica en la presentación del DiPELE, se prestó especial atención a la microestructura de este diccionario para que fuera fácilmente comprendida por un público no nativo. Esto se puede observar con los ejemplos, que «se han obtenido del Corpus Vox-Bibliograf, si bien muchos de ellos han sido adaptados, retocados o matizados para adecuarlos a los fines de nuestra obra» (Moreno Fernández, 1995: XVI). Por todo lo que se expone y analizando diversos términos, se pueden extraer los siguientes datos: el DiPELE recoge información sobre la ortografía (escritura de la palabra), pronunciación (uso del alfabeto fonético internacional), silabación (separación silábica de la palabra por medio de $\cdot$ ), homonimia (se recogen las diferencias de significado en términos homónimos, aunque no en voces diferentes), definiciones y ejemplos adaptados, información flexiva verbal ( $\mathrm{prnl}$.), información flexiva nominal $(m . \mathrm{y} f$.), información combinatoria sintáctica (tr.), información combinatoria semántica (la colocación banco de datos), significado y uso de las UFs (meter baza), relaciones paradigmáticas (se alude a la antonimia entre beneficiar y perjudicar) y marcas de uso (hum. fig., fam., INFORM.). Las tres únicas pautas que no aparecen en el DiPELE son: información orden de las palabras, puesto que no se explica la posición que ocupa la palabra baza dentro de la UF, si puede ser modificada o no, ni la información cultural. 
Finalmente, en relación a la iconoestructura el DiPELE reúne todas las características que se exponen en los criterios de evaluación: hay variedad de tipos de letra (la voz está resaltada en negrita, las marcas aparecen en cursiva, etc.), Además, se sigue un orden lógico en la distribución de las entradas y se utilizan símbolos y abreviaturas. Con respecto a las ilustraciones, algunas de ellas son útiles ya que explican las partes que componen el todo, como es el caso de bicicleta, en la cual se desglosan y se señalan todas las partes que la componen. Desafortunadamente, este no siempre es el caso y en se incluyen imágenes que carecen de valor pedagógico y que no ayudan al estudiante a entender mejor el significado del término, puesto que no añade información adicional sobre el término ni hace referencia a las distintas partes que lo componen, como es el caso del siguiente ejemplo:

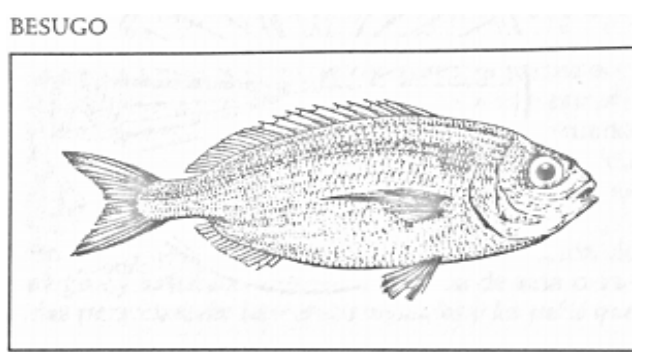

Figura 1. Ilustración de besugo en el DiPELE (Alvar Ezquerra, 1995: 143).

\subsubsection{Análisis del $V O X / N T C$}

Por otra parte, si se aplican los parámetros que Haensch propone para analizar los diccionarios bilingües, se obtienen los siguientes resultados. En primer lugar, el título en sí, Vox English and Spanish Learner's Dictionary, puede inducir a error, puesto que los diccionarios de aprendizaje en inglés se denominan learner's dictionaries. Además, no se establece a qué perfil de estudiante de inglés o español va dirigido, ya que en el prólogo se defiende que «este diccionario contiene toda la información que necesita el usuario, ya sea principiante, intermedio o avanzado». Con respecto a la introducción gramatical, hay una introducción gramatical a la lengua inglesa (hecha en español) y otra a la lengua española (en inglés). La fonética, por su parte, solo está presente en la parte de inglés a español. Con respecto a las instrucciones para el usuario, este diccionario proporciona una guía para consultar el diccionario en ambas direcciones. Además, se indica a qué categoría pertenecen las palabras, ( $a d j ., a d v$., subj., etc.), su género (f., m., neutr.,) y el régimen preposicional de verbos ( $t$. [transitivo], $i$., [intransitivo]). Cabe destacar que se usan marcas como iron., (irónico), $A M$ (español de América), $\rightarrow$ (veáse) y $\approx$ (aproximadamente equivalente $a)$.

Con respecto al sexto punto, hay presencia de fraseología en ambas direcciones. En inglés: his bark is worse than his bite> perro ladrador, poco mordedor (VOX/NTC, 1998: 39), en español, irse al otro barrio > jam to kick the budget. La fraseología, en ambos casos, viene precedida por un círculo relleno, aparece en negrita en la lengua origen y en cursiva en la lengua meta. En el caso de haber una entrada en la que se haga referencia a una UF, puede estar acompañada de un ejemplo (i.e en bala, se hace referencia a 'como una bala', en la que se usa el ejemplo 'mi moto va como una bala'>'my new motorbike goes like a bullet'). Sin embargo, esto no siempre se cumple, ya que la entrada barba cuenta con un total de seis UFs y tan solo se aporta un ejemplo de 'con toda la barba' 
('es un caballero con toda la barba). De este modo, hay UFs como 'subirse a las barbas' o 'por barba' en las que tan solo se proporciona una traducción. Si nos atenemos a las marcas que se proporcionan en el diccionario, el lenguaje coloquial y vulgar está representado por las marcas fam y pey/pej (peyorativo, despectivo) en ambas direcciones. Los americanismos tienen su representación en ambas direcciones. En la parte españolinglés, los términos che y chícharo, entre otros, cuentan, con la marca AM.

En relación al punto noveno, en los diccionarios bilingües, se ponen en relación dos o más unidades lingüísticas idénticas o casi idénticas entre los idiomas en cuestión que son consideradas equivalentes lingüísticos. Esto, especialmente en la fraseología, es una ardua tarea puesto que al traducir una unidad fraseológica de un idioma a otro, esta puede perder toda su carga idiomática y, por ende, gran parte de su significado (LewandowskaTomaszczyk, 1990: 183-187). En este diccionario, normalmente, se da un solo equivalente en los sustantivos, adjetivos y adverbios, el más próximo en todos los casos. En relación a la fraseología, en ciertas ocasiones se proporcionan UFs inexistentes en la lengua inglesa ('to go like a bullet', 'a head each') debido a la traducción literal de las mismas.

Se registran abreviaturas y siglas tanto en la parte inglés-español (BAFTA) como en la parte español-inglés $(U G T)$. Cabe destacar que se recogen siglas de partidos políticos regionales españoles, como $U V$ (Unión Valenciana). En el caso de los homónimos, estos se presentan en diferentes voces según la etimología de cada término. No se recogen ni la $<\mathrm{ch}>$ ni la $<1 \mathrm{ll}>$, ateniéndose al modelo de alfabetización internacional. Finalmente, se incluyen culture specific words, palabras difícilmente traducibles dada su gran carga cultural e idiomaticidad. Ejemplos de estos tipos de palabras pueden ser bandurria o bailaor/a. Bandurria no se traduce, mientras que bailaor/a se traduce como flamenco dancer. No se hace referencia a falsos amigos. Con respecto al último punto, no hay evidencias de ninguno de los extras mencionados en este diccionario.

\subsection{Análisis contrastivo del DiPELE y VOX/NTC}

En primer lugar, en relación con el grupo de estudiantes al que va dirigido, el DiPELE hace especial hincapié en que es un diccionario puente en el aprendizaje del español como lengua extranjera entre el diccionario bilingüe y el diccionario monolingüe general (Moreno Fernández, 1995: IX). Por su parte, el VOX/NTC simplemente se limita a señalar que puede ser utilizado por cualquier estudiante de español que quiere aprender inglés y viceversa.

En referencia a las similitudes y diferencias existentes en las hiperestructuras de ambas obras lexicográficas, la guía de uso en ambos diccionarios ocupa dos páginas completas. En estas, el DiPELE cuenta con 22 indicaciones, mientras que el VOX/NTC con 23. Sin embargo, la mayoría de las indicaciones difieren de un diccionario a otro y solo son comunes a ambos las referentes a la fraseología, régimen preposicional, subentrada y categoría gramatical, lo que denota una diferenciación en la microestructura. Con respecto a las abreviaciones, el DiPELE cuenta con un total de 108, 39 de ellas son marcas técnicas, mientras que el $V O X / N T C$ con 96, 43 de marcas técnicas. Tan solo se comparten 25 marcas técnicas y, aunque la mayoría de ellas comparten la misma abreviatura, no siempre es así, ya que hay divergencias: en el DiPELE, aeronáutica es $A E R O N$, mientras que en $N T C / V O X$, es $A E R$.

Los apéndices gramaticales incluyen, a grandes rasgos, la misma información, aunque se estructura de una manera diferente y suele ser más limitada en el caso del diccionario 
bilingüe. Evidentemente, en el $V O X / N T C$, al ser un diccionario bilingüe se compara la noción de sustantivo en español con el inglés, mientras que en el DiPELE se proporciona una explicación detallada sin establecer ninguna comparación con otro idioma. Cabe destacar que el $V O X / N T C$ incluye algunas características que no aparecen en el DiPELE, principalmente relacionadas con problemas en la escritura del español. La principal similitud de estos diccionarios en esta parte se encuentra en el apartado de los verbos irregulares en español: ambos cuentan con 92 verbos irregulares, no ordenados alfabéticamente, que son los mismos tanto en uno como en otro diccionario y que, además, aparecen en la misma posición.

Ateniéndonos al número de voces que componen ambos diccionarios, el DiPELE cuenta con 22000 voces que han pasado un filtro de selección y cuyas definiciones se elaboran a partir de un vocabulario restringido de 2000 palabras para facilitar la comprensión de los usuarios del diccionario. Por otra parte, el VOX/NTC no es nada claro a la hora de proporcionar el número exacto de voces que posee. En la contracubierta, en inglés, se menciona que cuenta con «casi 100.000 términos y expresiones y más de 118.000 sentidos», mientras que en el prólogo se alude a que el diccionario «ofrece más de 160.000 traducciones». No se hace referencia al criterio que se ha seguido a la hora de seleccionar las voces con las que cuenta el diccionario, así como sus respectivas traducciones.

Para comprobar si se registran las mismas voces o no en estos diccionarios, se han tomado como referencia las letras - b y - u del DiPELE y de la parte español-inglés del $N T C / V O X$. Al contabilizarse en una base de datos, en la letra -b del DiPELE se recogen un total de 863 voces, por las $1311 \mathrm{del} N T C / V O X$. Por su parte, la letra -u del DiPELE cuenta con 119 voces, mientras que la del $N T C / V O X$ con 242 . Estas obras lexicográficas comparten, mayoritariamente, el número de voces que se recogen, aunque hay desajustes. En la letra -b, hay 17 voces que aparecen en el DiPELE y no en el VOX/NTC, mientras que en la u solo hay 2 términos no comunes. Cabe destacar que hay dos parámetros comunes en estas: responden a tecnicismos y palabras con una escasa frecuencia. Por ejemplo, se recogen voces relacionadas con el ámbito de la política (bicameral), química (benzol), agricultura (besana) o poesía (bucólica) y otras de escasa frecuencia, como banasto, ballico o bieldo; con 2, 7 y 22 apariciones respectivamente en el Corpus del Español.

La microestructura arroja diferencias significativas. En el DiPELE, se hace una división silábica de los términos, se incluye una transcripción fonética (en el $V O X / N T C$ tan solo se hace en la parte inglés-español), se proporciona una definición, un ejemplo (aunque en el $V O X / N T C$ los hay no es la tónica general), se incluyen observaciones sobre el uso recomendado por parte de la RAE y se establecen relaciones de sinonimia y antonimia con otros términos. Otras divergencias se pueden encontrar en las marcas que se utilizan en los diccionarios. Términos como barbarismo (lingüística), uranio (química) y útero (anatomía) aparecen con sus respectivas marcas en el DiPELE, mientras que en el $V O X / N T C$ no se registran, a pesar de la existencia de dichas marcas en este diccionario.

El tratamiento de la homonimia también se hace de manera diferente en ambas obras lexicográficas. En el DiPELE, se engloban todas las acepciones bajo una misma voz, sin establecer una diferencia entre polisemia y homonimia. Por esta razón, en términos como botín, se engloban todas las acepciones sin establecer ninguna diferenciación etimológica entre botín 1 (derivado de bota) y botín 2 (cuya etimología proviene del germánico: bytin (presa)). Por su parte, en el $V O X / N T C$ si se reseña la homonimia al existir dos voces diferentes para este término. 
Asimismo, se pueden observar diferencias considerables en el tratamiento de la fraseología. No siempre se comparten las mismas UFs, como se puede observar en bacalao. El DIPELE recoge únicamente la UF partir el bacalao (fam.), mientras que en el $V O X / N T C$ se recogen cortar el bacalao y ite conozco bacalao!, ninguna de ellas con marcas de ningún tipo. En el término borda, en el DIPELE no hay ninguna referencia a la fraseología, sin embargo, en el VOX/NTC hay evidencia de dos UFs: irse por la borda y tirar por la borda. A su vez, cabe destacar que este término va seguido de la marca $M A R$. Sin embargo, el término bala cuenta con la misma fraseología e, incluso, con el mismo ejemplo en ambos diccionarios. La traducción que se aporta al inglés de la UF ir como una bala se limita a ser una traducción literal al inglés, para obtener, de este modo otra UF en lengua inglesa. Sin embargo, esta UF (to go like a bullet) no existe en lengua inglesa.

Finalmente, con respecto a la iconoestructura, la gran diferencia entre estas obras lexicográficas radica en que el $V O X / N T C$ no aporta ilustraciones de ningún tipo a lo largo de su obra, mientras que el DiPELE cuenta con un total de 193 ilustraciones.

\section{Interpretación de los datos}

En lo que se refiere a la hiperestructura, ambos diccionarios aportan una guía de consulta clara y específica para ayudar a la comprensión y uso por parte del usuario. Con respecto a los apéndices gramaticales, aunque similares, los del DiPELE son bastante más detallados y explicativos que los del $V O X / N T C$. Si se toma en cuenta al público al que debería de ir dirigido cada diccionario, el $V O X / N T C$ debería de contar con un apéndice más amplio, ya que va dirigido a usuarios de nivel inicial. Además, no aportan una explicación de uso en muchos aspectos y para explicar la diferencia entre tú y usted, este diccionario se limita a decir simplemente que usted es el pronombre de cortesía. Sería conveniente, y más para un público cuya lengua materna es el inglés, ahondar en este aspecto y aportar información de carácter pragmático que clarificase cuándo y cómo se usa. Un acierto de este apéndice gramatical es que está explicado en inglés y hace referencia a problemas relacionados con la escritura, el acento y la distinción entre diptongos, triptongos e hiatos. En ambos diccionarios, se echa en falta una explicación sobre la fonética en el español. Bien es cierto que en el DiPELE se ofrece un capítulo íntegro acerca de la fonética, sin embargo, no se hace referencia en ningún momento a las posibles variedades fonéticas que existen en el español, las cuales son totalmente pertinentes. Finalmente, también se echan en falta apéndices culturales que hagan referencia a países de habla hispana.

Con respecto a la macroestructura, el DiPELE es claro con el número de voces qué selecciona y con los parámetros a los que se atiene para su selección. Además, se explica de qué manera se elaboran las definiciones y los ejemplos. Puede ser discutible el uso diversos tecnicismos y palabras de escasa frecuencia, que difícilmente van a ser utilizados por un extranjero con un nivel intermedio-avanzado. Por su parte, el $N T C / V O X$ no es claro en ningún momento con el número de voces que contiene en cada dirección, ni qué criterios se han elegido para su elección. Se limita tan solo a resaltar que cuenta con alrededor de 100.000 términos sin ahondar en ello, lo que parece ser una estrategia comercial al mostrar un número tan elevado de términos.

Bien es cierto que el número de términos de las letras que se han analizado son mayores en el $V O X / \mathrm{NTC}$, sin embargo, en este diccionario se incluyen, por ejemplo, tres voces diferentes para bacon, bacón y beicon. Aunque el estudiante debe ser consciente de que 
se puede encontrar estas grafías en español, se podría haber hecho referencia a ello en una sola voz. Por su parte, en el DiPELE, se recoge tan solo la forma beicon. Un acierto del $V O X / N T C$ frente al DiPELE es la inclusión de americanismos (puede ser que influido porque su lanzamiento tuvo lugar en Estados Unidos en lugar de España) y de siglas, de las que carece el DiPELE, y que pueden ser más útiles para un estudiante de español de nivel medio-avanzado que otras voces que se han incluido.

La microestructura del DiPELE se adapta a lo que se espera de un diccionario de estas características. Quizá, lo más destacable y digno de mención sean las definiciones fácilmente comprensibles, lo cual se ha logrado a partir de un excelso trabajo puesto que todas estas definiciones están claramente adaptadas al público al que van dirigido. Además, la presencia de ejemplos en cada acepción, clarifica su significado y es remarcable que estos son extraídos del corpus de la propia editorial y adaptados cuando es necesario. Otra virtud de este diccionario es la presencia de la sinonimia. Como principales defectos, este diccionario solo aporta la transcripción fonética según el español estándar y no hace referencia a posibles cambios de pronunciación en otras variedades del español habladas por millones de hispanoparlantes, la no división de los homónimos en voces diferentes y la escasa o nula información cultural que se aporta. Por su parte, en el $V O X / N T C$, se dice que los ejemplos son abundantes aunque, la presencia de los ejemplos es bastante reducida y la mayoría de las voces quedan sin ser ejemplificadas. Además, no se explica qué criterios se han seguido para la elección de los mismos. Su punto más fuerte con respecto al DiPELE es la separación de las palabras homónimas en dos voces diferentes.

Finalmente, en la iconoestructura, ambos diccionarios presentan diferentes tipos de letra para favorecer su lectura y comprensión. Con respecto a las imágenes, solo el DiPELE cuenta con ellas y, aunque algunas pueden ser clarificadoras, hay otras que no ayudan a entender mejor el significado del término al no aportar información adicional sobre el mismo. En caso de presentar imágenes, todas deberían contar con un marcado contenido pedagógico y clarificador para que su presencia estuviera justificada.

A la luz de este análisis, se puede comprobar que no hay un volcado de la edición del diccionario de aprendizaje publicado por $V O X$ en el año 1995 a la edición bilingüe que esta misma editorial lanzó al mercado tres años después ya que, aunque estos diccionarios presentan algunas similitudes entre sí, presentan características que nos inducen a pensar en que no se ha tomado como referencia el DiPELE en la elaboración del $V O X / N T C$, como las evidentes diferencias en la macroestructura, microestructura e iconoestructura. Sin embargo, cabe destacar que el título del VOX/NTC evoca a los diccionarios de aprendizaje y no a los bilingües, al ser denominado como Vox English and Spanish Learner's Dictionary, hecho que sí podría tener su origen en el DiPELE.

En términos generales, el DiPELE parece ser un diccionario más apropiado para el público al que va dirigido que el $V O X / N T C$. En primer lugar, este diccionario, es claro en todo momento con el público al que va dirigido: a un público extranjero o nativo que está en una fase intermedia del aprendizaje del español y que busca mejorar su competencia. Por lo tanto, deja claro que es un diccionario puente entre el nivel inicial y el avanzado, ya que este no puede ser aprovechado por estudiantes de nivel inicial, que tienen que usar un diccionario bilingüe al no poseer la suficiente competencia para comprender un diccionario monolingüe, ni por los de los niveles más avanzados, que precisan de un diccionario monolingüe general. A su vez, el DiPELE supera la clasificación propuesta 
por los lexicógrafos Azorín Fernández y Martínez Egido (2010) en la mayoría de sus puntos. Sus principales defectos, a mi criterio, son la ausencia de una guía de conversación e información cultural en la hiperestructura, la no inclusión de siglas ni americanismos en la macroestructura; no recoger las palabras homónimas en voces diferentes ni mencionar posibles diferencias en la pronunciación del término en la transcripción fonética en la microestructura y el poco valor pedagógico de algunas de sus ilustraciones en la iconoestructura. Estos defectos se podrían haber paliado en la edición más reciente del diccionario, del año 2010, en lugar de haber realizado una mera reimpresión de la edición que se está analizando (1995).

Por su parte, el $V O X / N T C$ engloba a cualquier estudiante de inglés que esté estudiando español o viceversa, sin establecer ningún tipo de diferencia en el nivel que estos tengan. Esto, así como destacar con que se cuentan con alrededor de 100.000 términos y más de 118.000 sentidos sin establecer si son en cada dirección o en total, parece ser que tiene una clara finalidad comercial, ya que de este modo busca ampliar su público y señalar que cuenta con un número muy elevado de términos en comparación a otros diccionarios existentes. Este diccionario, a pesar de contar con fraseología, en ciertas ocasiones se limita a exponer una traducción literal al inglés de la UF en cuestión, a pesar de que esta no exista en lengua inglesa. Los ejemplos, a su vez, son escasos, aunque se señale en la contraportada que haya ejemplos abundantes. Otro defecto de este diccionario es la no inclusión de ningún tipo de imágenes. Sin embargo, no todo son aspectos negativos, puesto que sí se aportan marcas de uso, se da una traducción, normalmente, adecuada y precisa ( voces diferentes, se incluyen culture specific words y hay presencia de siglas $\mathrm{y}$ americanismos.

\section{Conclusiones}

En esta investigación se han expuesto las diferencias existentes entre dos categorías de obras lexicográficas por las que debe pasar un estudiante extranjero en cualquier idioma analizando un diccionario bilingüe y otro de aprendizaje publicados por la misma editorial en un periodo de tiempo muy cercano con parámetros propuestos por expertos en la materia. De este modo, se ha demostrado que DiPELE se asemeja más a un diccionario ideal de aprendizaje que el VOX/NTC a uno bilingüe y que el DiPELE es mucho más honesto con el cliente potencial que duda en si comprar o no el diccionario, puesto que deja claro el número de voces que contiene, qué parámetros se siguen en su elaboración y a quién va dirigido a diferencia del $V O X / N T C$, a pesar de que la edición más reciente del DiPELE sí responda claramente a un carácter comercial.

Es digno de mención que en numerosas ocasiones el estudiante cae en el error de adquirir un diccionario que no se ajusta a sus necesidades que, por lo tanto, acarrea que el progreso en la lengua extranjera se ralentice. Lo más grave de este hecho es que el usuario se guía mayormente por el consejo del docente, que recomienda de manera negligente al estudiante debido al desconocimiento general que hay por parte del profesorado sobre los diccionarios de aprendizaje en lengua española. Bien es cierto que la trayectoria de esta clase de obras lexicográficas en español, por lo que se espera que la calidad de los diccionarios de aprendizaje mejore con el paso del tiempo en la lexicografía española y que estos se adapten a los tiempos que corren.

Sin lugar a dudas, hay aspectos que son francamente mejorables en esta investigación: se podrían haber escogido obras lexicográficas más cercanas cronológicamente a la 
actualidad con las que, quizás, se hubiera obtenido un resultado diferente. Se ha querido tomar el DiPELE como referencia porque este diccionario es la obra por antonomasia de este género, ya que representa el punto de partida en los diccionarios de aprendizaje en español. La selección de diccionarios más recientes abre una futura vía de investigación, en la que también se podría considerar realizar un estudio contrastivo entre otros diccionarios de aprendizaje existentes en la lexicografía española para comprobar cuál es el que más se asemeja a la clasificación propuesta por Azorín Fernández y Martínez Egido. A su vez, se podría comparar el diccionario $V O X / N T C$ con otros diccionarios bilingües editados por la misma editorial.

\section{Bibliografía}

\section{a) Fuentes primarias}

Alvar EzQuerra, M. (1995). Diccionario para la Enseñanza de la Lengua Española. Alcalá de Henares: Bibliograf-Vox.

VOX/NTC Publishing (1998). Vox English and Spanish Learner's Dictionary. Chicago: Vox/NTC Publishing.

\section{b) Fuentes secundarias}

Alvar EzQuerra, M. (1993). «Los diccionarios bilingües: su contenido”. En Lexicografía descriptiva (pp. 145-164). Barcelona: Bibliograf-Vox.

Azorín Fernández, D. y Climent DE Benito, J. (2005). apud D. Azorín Fernández y J. J. Martínez Egido (2010). «El diccionario como instrumento didáctico en la enseñanza/aprendizaje de E/LE». En Actas del XXI Congreso de la Asociación Española de Lingüística Aplicada (AESLA) (pp. 671-694). Santiago de Compostela: Publicaciones de la Universidad de Santiago de Compostela.

Azorín FernándeZ, D. y MARTínez EgIDO, J. J. (2010). "Sobre la utilidad de los diccionarios monolingües de aprendizaje». En Ruhstaller, S. y Gordón Peral, M. D. (coords.); Diccionario y aprendizaje del español (pp. 89-132). Berna: Peter Lang.

CONTRERAS IZQUIERDO, N. (2000). «El diccionario en la enseñanza del español como L2: el papel del usuario». En IV Congreso de Lingüistica General, Cádiz del 3 al 6 de abril 2000 (pp. 657-666). Cádiz: Universidad de Cádiz.

CORPUS DEL ESPAÑOL (2011-). https://www.corpusdelespanol.org/now/ [Fecha de consulta: 30/05/2019].

Dubois, J. y C. (1971). Introduction à la lexicographie: Le dictionaire. Paris: Larousse.

HAENSCH, G. (2003-2004). «La lexicografía bilingüe en la actualidad y su valoración», Revista de lexicografía, 10,133-138.

HERNÁNDEZ HeRnÁNDEZ, H. (1990). «Hacia un modelo de diccionario monolingüe de español para extranjeros». En Español como lengua extranjera: aspectos generales. Actas del I Congreso Nacional de ASELE (pp. 159-166). Granada: Universidad de Granada.

InSTITUTO CERVANTES (2018). El español: una lengua viva. Informe 2018. Madrid: Instituto Cervantes. 
LEWANDOWSKA-TOMASZCZYK, B. (1990). «Meaning, synonymy, and the dictionary». En Lewandowska-Tomaszczyk, B. y Tomaszczyk, J. (eds.); Linguistic and literary studies in Eastern Europe, Volume 28: Meaning and Lexicography (pp. 181-208). Ámsterdam/Filadelfia: John Benjamins.

Moreno Fernández, F. (1995). «Presentación». En Diccionario para la Enseñanza de la Lengua Española (pp. IX-XVIII). Alcalá de Henares: Biblograf-VOX.

PABLO NúÑEZ, L. (2017). "Los elementos culturales en los diccionarios de español para extranjeros». Revista de Educación de la Universidad de Granada, 24, 203-226.

Prado Aragonés, J. (2005). «El Uso del diccionario para la enseñanza de la lengua: consideraciones metodológicas». Kañina, Rev. Artes y Letras, Costa Rica, 29, 19-28.

RoDRÍGUEz BARCIA, S. (2016). Introducción a la Lexicografía. Madrid: Síntesis.

SAla CAJA, L. (2015). «Actitudes de estudiantes y profesores hacia los diccionarios electrónicos portátiles». En Morimoto, Y., Pavón Lucero, M. V. y Santamaría Martínez, R. (eds.); La enseñanza de ELE centrada en el alumno (pp. 855-863). Getafe: Asociación para la enseñanza del Español como Lengua Extranjera. 